\title{
Enhancement of Drought-Stress Tolerance of Brassica oleracea var. italica L. by Newly Isolated Variovorax sp. YNA59
}

\author{
Yu-Na Kim ${ }^{1}$, Muhammad Aaqil Khan' ${ }^{1}$, Sang-Mo Kang ${ }^{1,2}$, Muhammad Hamayun ${ }^{3}$, and In-Jung Lee ${ }^{1 *}$ \\ 'School of Applied Biosciences, Kyungpook National University, Daegu 41566, Republic of Korea \\ ${ }^{2}$ Institute of Agricultural Science and Technology, Kyungpook National University, Daegu 41566, Republic of Korea \\ ${ }^{3}$ Department of Botany, Abdul Wali Khan University, Mardan, Pakistan
}

Drought is a major abiotic factor and has drastically reduced crop yield globally, thus damaging the agricultural industry. Drought stress decreases crop productivity by negatively affecting crop morphological, physiological, and biochemical factors. The use of drought tolerant bacteria improves agricultural productivity by counteracting the negative effects of drought stress on crops. In this study, we isolated bacteria from the rhizosphere of broccoli field located in Daehaw-myeon, Republic of Korea. Sixty bacterial isolates were screened for their growth-promoting capacity, in vitro abscisic acid (ABA), and sugar production activities. Among these, bacterial isolates YNA59 was selected based on their plant growth-promoting bacteria traits, $A B A$, and sugar production activities. Isolate YNA59 highly tolerated oxidative stress, including hydrogen peroxide $\left(\mathrm{H}_{2} \mathrm{O}_{2}\right)$ and produces superoxide dismutase (SOD), catalase (CAT), and ascorbate peroxidase (APX) activities in the culture broth. YNA59 treatment on broccoli significantly enhanced plant growth attributes, chlorophyll content, and moisture content under drought stress conditions. Under drought stress, the endogenous levels of ABA, jasmonic acid (JA), and salicylic acid (SA) increased; however, inoculation of YNA59 markedly reduced ABA (877 $\pm 22 \mathrm{ng} / \mathrm{g})$ and JA $(169.36 \pm 20.74 \mathrm{ng} / \mathrm{g})$ content, while it enhanced SA levels $(176.55 \pm 9.58 \mathrm{ng} / \mathrm{g})$. Antioxidant analysis showed that the bacterial isolate YNA59 inoculated into broccoli plants contained significantly higher levels of SOD, CAT, and APX, with a decrease in GPX levels. The bacterial isolate YNA59 was therefore identified as Variovorax sp. YNA59. Our current findings suggest that newly isolated drought tolerant rhizospheric Variovorax sp. YNA59 is a useful stress-evading rhizobacterium that improved droughtstress tolerance of broccoli and could be used as a bio-fertilizer under drought conditions.

Keywords: Variovorax sp. YNA59, drought stress, phytohormones, antioxidant activity, broccoli

Received: June 9, 2020 Accepted: August 10, 2020

First published online: August 13, 2020

*Corresponding author Phone: +82-53-950-5708 Fax: +82-53-953-6880 E-mail: ijlee@knu.ac.kr

Supplementary data for this paper are available on-line only at http://jmb.or.kr.

pISSN 1017-7825 eISSN 1738-8872

Copyright(C) 2020 by The Korean Society for Microbiology and Biotechnology

\section{Introduction}

Plants are constantly exposed and challenged by various environmental stresses throughout their life cycle. Among these environmental stresses, drought stress causes significant losses to agricultural productivity [1], as it reduces germination rates, seedling height, leaf area, and crop growth [2-4]. In China, drought stress reduced more than $30 \%$ of corn yield [5], while reduction in maize yield ( $40 \%$ ), and wheat (21\%) were recorded during $40 \%$ of water reduction [6]. Similarly, a 34\%-68\% yield reduction in cowpea depending on the timing of drought stress [7]. Drought stress leads to the generation of reactive oxygen species (ROS) such as superoxide anion $\left(\mathrm{O}^{2-}\right)$, hydrogen peroxide $\left(\mathrm{H}_{2} \mathrm{O}_{2}\right)$, and hydroxyl radical $(\mathrm{HO})$ and cause oxidative damage to cell components, lipid and protein peroxidation, and enzyme inhibition eventually leading to cell death $[8,9]$. Drought tolerance may be improved through various methods, including plant breeding, chemical fertilizer, tissue culture, and genetic engineering, which are time consuming, costly, and have adverse effects on the environment.

The use of plant growth-promoting rhizospheric bacteria (PGPR) is an ecofriendly approach for improving agricultural productivity by easing the negative effect of drought stress on economically important plant species worldwide. PGPR can improve drought tolerance by regulating phytohormone production, biological nitrogen fixation, the production of siderophores, hydrogen cyanide (HCN), ammonia, and phosphate solubilization [10, 11]. The secondary metabolite secreted by PGPR strengthens plant resistance to various stressors and promotes growth and yield attributes of treated plants grown under drought conditions. Previously, several researchers have reported the use of PGPR to ease drought stress in plants such as Lavandula dentate [12], soybean [13], maize [14], and basil plants [15].

Brassica oleracea var. italica L. belongs to the family Brassicaceae, and is recognized for its health benefits, 
provision of a good source of bioactive phytochemicals, and consumed as vegetable worldwide [16]. The chemical composition of broccoli makes it popular for human diet because it contains secondary metabolites (glucosinolates and flavonoids), protein, carbohydrates, minerals, and vitamins. According to previous research, drought stress severely affects broccoli growth, biomass, and yield $[17,18]$. The application of bio-stimulants and nitric oxide also enhances drought stress tolerance in broccoli $[19,20]$, while the inoculation of PGPR enhanced growth attributes, and biomass under normal condition [21-23]. There is no previous report regarding the application of PGPR to broccoli under drought stress. In this study, we evaluated the effect of PGPR on the physiological traits, endogenous phytohormones, and antioxidant levels of broccoli grown under PEG induced drought stress conditions.

\section{Materials and Methods \\ General Procedure}

Bacteria were isolated from the rhizosphere of broccoli field in Daehaw-myeon, Gangwon-do, Republic of Korea (latitude $37^{\circ} 32^{\prime} 20.3^{\prime \prime N}$, longitude $128^{\circ} 27^{\prime} 05.8^{\prime \prime} \mathrm{E}$ ). One g of soil sample was suspended in $9 \mathrm{ml}$ of sterilized $0.85 \% \mathrm{NaCl}$ and the suspensions were serially diluted up to $10^{-5}$ as previously described $[24,25]$. All isolates were screened for different plant growth-promoting traits. Orange media test was used to check the catalase production ability of the isolates. The composition of orange media was $100 \mathrm{ppm}$ reactive orange16, lysogeny broth (LB), and agar $1.8 \%$ [26]. Congo red assay was used to confirm the formation of bacterial exopolysaccharides (EPS) [27]. Assay plates were prepared with LB broth $(25 \mathrm{~g} / \mathrm{l})$, sucrose (5\%), agar $(2 \%)$, and Congo red $(0.8 \mathrm{~g} / \mathrm{l})$, autoclaved, inoculated, and incubated for 5 days at $37^{\circ} \mathrm{C}$. Six concentrations of PEG $6000(0,5,10,15,20$, and $25 \%)$ were prepared and $0.1 \%$ of culture aliquot was inoculated into $5 \mathrm{ml}$ of sterilized LB broth and incubated in a shaking incubator at $30^{\circ} \mathrm{C}$. The optimal density was measured using T60 UV-Vis spectrophotometer (PG Instruments Ltd., UK) at $600 \mathrm{~nm}$. On the basis of screening results, bacterial isolate YNA59 was selected for further detailed study.

\section{In vitro Quantification of Abscisic Acid and Sugar Content of Bacterial Isolate YNA59}

Bacterial isolate YNA59 was grown on LB media for 3 days, centrifuged (5000 $\times g ; 15 \mathrm{~min}$ ) culture filtrate was analyzed for ABA and sugar contents. For ABA measurement, following the method previously published by Khan et al. $[25,28]$. The concentration of ABA content was calculated by comparing with the known standard using the gas chromatography/mass spectrometry with selected ion monitoring (GC/MS SIM)

For sugar content, the method described by Kang et al. [29] was followed. $1.5 \mathrm{ml}$ of isolate YNA59 culture, which was incubated for 5 days at $30^{\circ} \mathrm{C}$ was centrifuged $(8000 \mathrm{rpm} ; 10 \mathrm{~min}$ ), filtered through Sep pack $\mathrm{C} 18$ cartridge and $0.45 \mu \mathrm{m}$ Nylon-66 syringe filters and analyzed through high-performance liquid chromatographic (HPLC) technique.

\section{Stress Media Test of YNA59}

Isolate YNA59 was tested for tolerance to multiple oxidative stresses. Oxidative stress test was conducted by following the method of Park et al. [30] by supplementing LB agar media with different concentrations of hydrogen peroxide $(0 \mathrm{mM}-2 \mathrm{mM})$. For superoxide dismutase (SOD) measurement, SOD Assay Kit-WST (Dojindo Co. Ltd, Japan) was used, while the catalase activity was determined using the Amplex Red Catalase Assay Kit (Molecular Probes, Thermo Fisher, USA). Ascorbate peroxidase (APX) was determined according to the method described by Khan et al. [31] by measuring the absorbance at $290 \mathrm{~nm}$ using a T60 UV-Vis Spectrophotometer.

\section{Growth Condition and Treatments}

Broccoli seeds were purchased from Asia Seed Korea Ltd, Seoul, Republic of Korea and sown in trays filled with autoclaved horticultural soil (which contained coco peat $51.5 \%$, peat moss $10 \%$, vermiculite $13 \%$, perlite $15 \%$, zeolite $10 \%$, humic acid, $0.1 \%$ fertilizer, and $0.4 \%$ fungus-free bio-soil, Gyeonggi-do, Shinsung Mineral Co., Ltd, Republic of Korea). After 2 weeks of germination, seedlings were transferred to pots $(10 \times 10)$ and were grown in a growth chamber at a temperature of $22^{\circ} \mathrm{C} \pm 0.5^{\circ} \mathrm{C}, 65 \%$ relative humidity, and light intensity of $200 \mu \mathrm{mol} \mathrm{m}^{-2} \mathrm{~s}^{-1}$ under long-day conditions ( $16 \mathrm{~h}$ of day time and $8 \mathrm{~h}$ of night time). The experimental design includes (a) W.C: Control- well watered ( $200 \mathrm{ml}$ water per week) (b) V.C: Bacterial treated ( $200 \mathrm{ml}$ cell suspension of isolate YNA59/ week), (c) W.D: drought stress $50 \mathrm{ml} /$ week (d) V.D: drought stress treated with $50 \mathrm{ml}$ YNA59/week. To test plant protection activity of YNA59 under drought stress, $50 \mathrm{ml}$ YNA59 $\left(4.0 \times 10^{8} \mathrm{cfu} / \mathrm{ml}\right)$ were inoculated via the soil drench method, while distilled water was used for control plants for 2 weeks. After stress completion, growth attributes and biomass were determined, plants were immediately harvested in liquid nitrogen and stored at $-80^{\circ} \mathrm{C}$ until further biochemical analyses. Before the harvest, chlorophyll contents were measured using the chlorophyll meter 300 (ADC BioScientific Ltd., UK).

\section{Quantification of Endogenous Phytohormones}

The endogenous phytohormones of plant samples were analyzed and quantified in a controlled environment. Endogenous ABA measurement was performed following an established protocol [32, 33]. Briefly, $0.1 \mathrm{~g}$ freezedried plant samples were extracted with isopropanol: acetic acid (95:5) filtered and added $50 \mathrm{ng} / \mathrm{ml}$ of ABA standard. The extracts were dried with $\mathrm{N}_{2}$ gas and methylated using diazomethane for ABA detection in a GC/MSSIM. Plant endogenous JA was quantified following the method of [24]. Alternatively, SA was extracted from freeze-dried broccoli samples following the protocol [34]. 
In-vivo Visualization of ROS in Broccoli Leaves

To visualize ROS damage, 3,3'-Diaminobenzidine (DAB) staining was conducted by following the protocol of [35]. The first and second leaves of broccoli, (highly damaged by drought stress) were incubated in $1 \%$ solution of DAB (Sigma Aldrich) and fully covered with broccoli leaves until the light and dark brown spots showed up. After incubation, leaves were bleached by boiling a decolorizing solution (acetic acid: glycerol: $96 \%$ ethanol = 1:1:3) to clearly visualize blue and brown spots, respectively, and after which they were photographed. All solutions were prepared in potassium phosphate buffer at $\mathrm{pH}$ 7.4.

\section{Quantification of Total Protein and Antioxidants}

For protein analysis, frozen fresh plant tissues were ground with ice-cold pestle and mortar, and then added to a solution of $50 \mathrm{mM}$ phosphate buffered saline, $0.1 \%$ polyvinylpyrrolidone (PVP), and $1 \mathrm{mM}$ ethylene diamine (EDTA). The homogenate was centrifuged at $10000 \times g$ for $10 \mathrm{~min}$ at $4^{\circ} \mathrm{C}$. The supernatant was immediately collected and used for protein and antioxidant enzyme quantification. For protein contents; Bradford [36] method was used in accordance with the BSA as a standard. Superoxide dismutase (SOD) was measured using SOD Assay Kit-WST, while catalase was determined. Ascorbate peroxidase (APX) and guaiacol peroxidase (GPX) was determined in accordance with the method described by Khan et al. [31] and Chaoui et al. [37] by measuring the absorbance at $290 \mathrm{~nm}$ and $470 \mathrm{~nm}$ using a T60 UV-Vis spectrophotometer.

\section{Identification of Bacterial Isolate YNA59}

Isolate YNA59 was incubated on cover glasses for 5 days. The cover glass pieces covered with a film of YNA59 were fixed with $2.5 \%$ glutaraldehyde for $2 \mathrm{~h}$ and washed with $0.1 \mathrm{M}$ sodium acetate buffer ( $\mathrm{pH} 7.3$ ). The glass pieces were dehydrated in ethanol $(20 \%, 50 \%, 70 \%, 80 \%, 90 \%$, and $100 \%)$ gradually. Before acquiring the field emission scanning electron microscope (FE-SEM) (Hitachi SU8220, Japan), the samples were sputter-coated with gold using an ion-sputtering device (JFC-110E, EC\&G, USA), and examined with FE-SEM [38]. Based on their best performance during the screening experiments, isolate YNA59 was selected for further experimentation and identification. For molecular identification, the method of Sambrook and Russell [39] was used for genomic DNA extraction, 16S rRNA-specific primers were used and amplified according to the protocol of Khan et al. [31]. The NCBI BLAST program was used to determine the homology of different nucleotide sequences of selected isolates, and MEGA 6.1 software was then used for phylogenetic analysis [40].

\section{Statistical analysis}

The results were statistically evaluated by analysis of variance using SAS 9.4 software. All analyses were repeated thrice with 14 plants per replicate. Duncan's multiple range tests were used to determine $95 \%$ confidence level.

\section{Results}

Isolation and screening bio-assay of bacterial isolates

A total of 60 bacterial isolates were collected from the rhizospheric soil of broccoli plants. The isolated bacteria were screened for different PGP traits, like the catalase assay, EPS formation, and PEG tolerance (Fig. S1. Orange media results showed that 18 bacterial isolates showed catalase activity (Fig. 1A and Fig. S1A). The bacterial isolates were further screened on Congo red assay, and 4 isolates showed positive results (Fig. 1B and Fig. S1B). The selected 4 isolates were then screened at different concentrations of PEG $(0 \%, 5 \%, 10 \%, 15 \%, 20 \%$, and $25 \%)$, and one isolate YNA59 showed the highest PEG induced drought tolerance (Fig. 1 and Fig. S 1C). Therefore, isolate YNA59 was selected for further investigations (Fig. 1).

\section{In vitro Abscisic Acid and Sugar Quantification of Isolate YNA59}

The culture filtrate of isolate YNA59 was quantified for ABA by using GC/MS and sugar content through HPLC. ABA results showed that isolate YNA59 produced a significant amount of ABA $(1.04 \pm 0.05 \mathrm{ng} / \mathrm{ml})$ (Fig. 2A). Sugar is the main component of polysaccharides; sugar quantification was conducted to estimate the

A

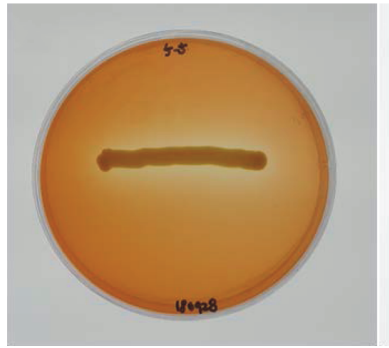

B

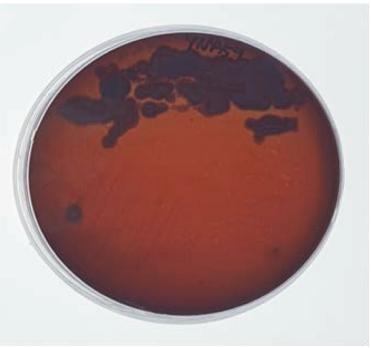

C

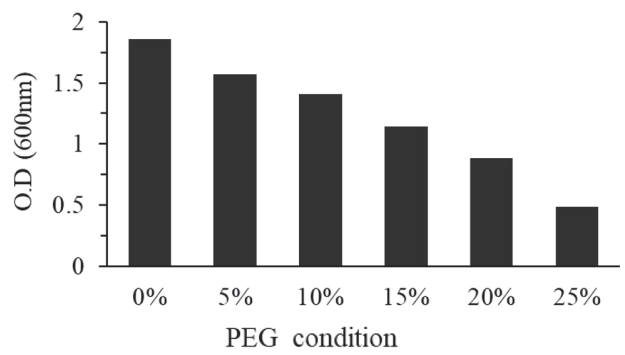

Fig. 1. Catalase and exopolysaccharide (EPS) activity as displayed on orange media and Congo red medium. (A) Shows the capability of catalase production, (B) EPS production, and (C) growth of isolate YNA59 at different concentrations of PEG6000. 

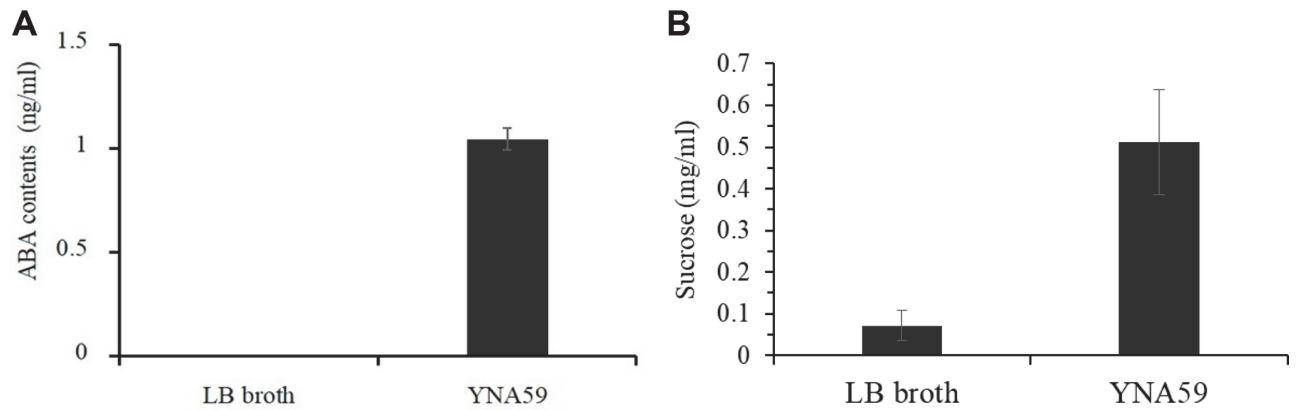

Fig. 2. Characteristics of bacterial isolates. (A) Quantification of abscisic acid (ABA) observed in culture broth (LB broth) of YNA59 and (B) Quantification of sucrose content in LB of YNA59. Each data point is the mean of three replicates. Error bars represent standard errors. The bars represented by different letters are significantly different from each other as evaluated by Duncan's multiple range tests (DMRTs).

bacterial EPS production. The results showed that isolate YNA59 produced a significant amount of sucrose $(0.51$ $\pm 0.12 \mathrm{mg} / \mathrm{ml})$ compared to the control $(0.07 \pm 0.003 \mathrm{mg} / \mathrm{ml})$ (Fig. 2B).

\section{Isolate YNA59 Oxidative Stress Tolerance}

Isolate YNA59 could tolerate high oxidative stress and grow efficiently on LB agar plates containing up to $2 \mathrm{mM}$ $\mathrm{H}_{2} \mathrm{O}_{2}$ (Fig. 3A). Similarly cultures broth analysis of isolate YNA59 indicates significantly higher SOD, CAT, and APX activities, demonstrating the presence of highly active antioxidant mechanism (Figs. 3B-3D).

\section{Bacterial Isolate YNA59 Regulates Broccoli Growth under Drought Stress}

Drought stress adversely affected the growth attributes of broccoli plants. However, isolate YNA59 significantly enhanced drought stress tolerance by regulating plant growth, plant biomass, and other biochemical attributes after 14 days of inoculation. Under drought stress, a decrease in plant height (30\%), leaf length (40.17\%), leaf width (34.73\%), fresh weight (61.23\%), and chlorophyll content (51.28\%) were observed. However, isolate YNA59 induced significant increase in plant height (12.14\%), leaf length (10\%), leaf width (14.51\%), fresh weight (23.18\%), and chlorophyll content (61.78\%) in drought stressed plants compared to the control (Fig. 4, Table 1).

Soil moisture content was also significantly higher in the YNA59-inoculated pots than the non-inoculated pots. The final soil moisture was measured 14 days after transfer, which showed that YNA59 treatment retained more soil moisture in drought stress pots (61\%) compared to the control (16.9\%) (Table 1).

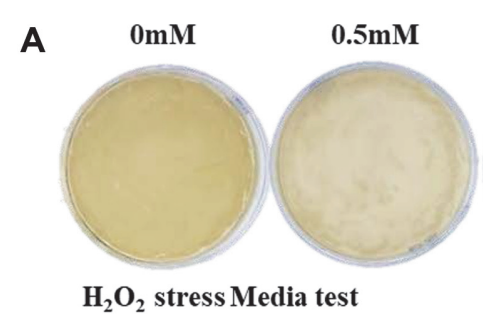

$\mathrm{H}_{2} \mathrm{O}_{2}$ stress Media test
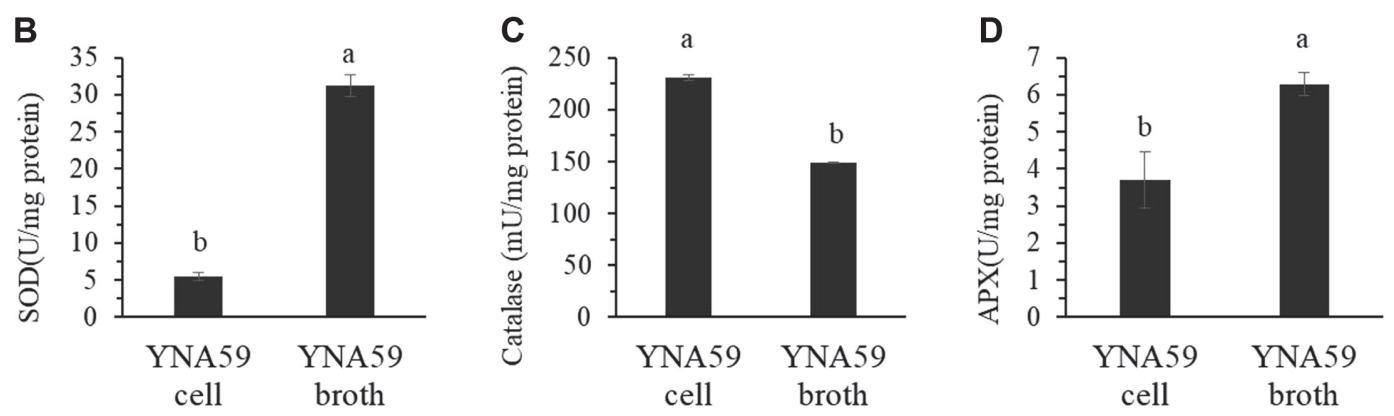

Fig. 3. Isolate YNA59 tolerance to oxidative stress. (A) showed resistance to $\mathrm{H}_{2} \mathrm{O}_{2}$, (B) produce significant amount of superoxide dismutase SOD activity, (C) Catalase activities (CAT) and (D) Ascorbic peroxidase (APX) in the YNA59 broth (culture filtrate) and YNA59 cell (pellets were mix in distilled water). Each data point is the mean of at least three replicates. Error bars represent standard errors. The bars presented with different letters are significantly different from each other as evaluated by DMRT. 


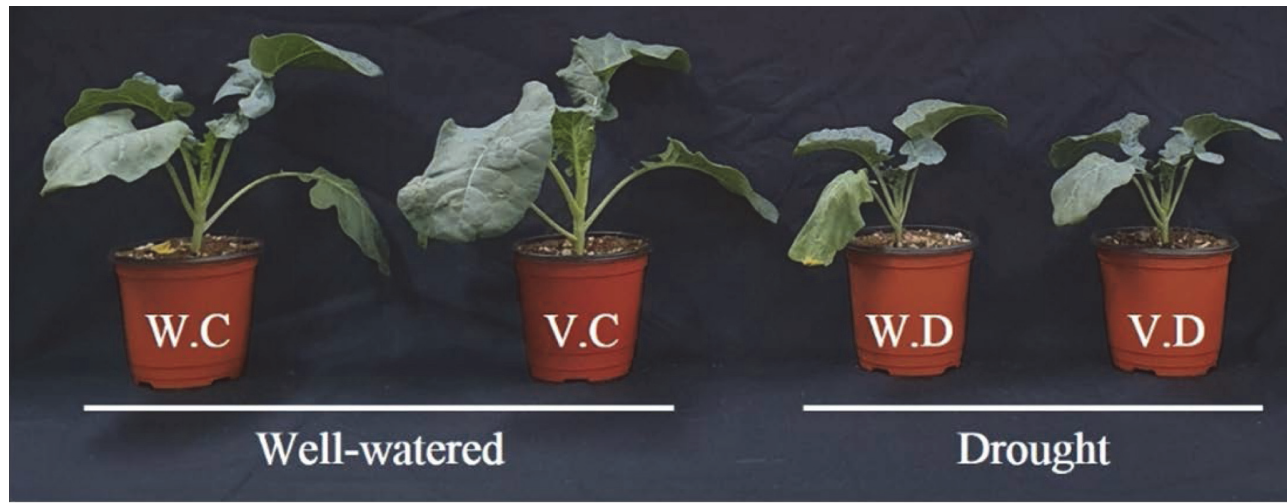

W.C : Water treated Control V.C : YNA59 inoculated Control

W.D : Water treated Drought V.D : YNA59 inoculated Drought

Fig. 4. Effects of selected bacterial isolate YNA59 on the growth of broccoli plants under normal and drought stress.

Table 1. Effects of selected bacterial isolate YNA59 on the growth of broccoli plants under normal and drought stress.

\begin{tabular}{ccccccc}
\hline Treatment & $\begin{array}{c}\text { Height } \\
(\mathrm{cm})\end{array}$ & $\begin{array}{c}\text { Leaf length } \\
(\mathrm{cm})\end{array}$ & $\begin{array}{c}\text { Leaf width } \\
(\mathrm{cm})\end{array}$ & $\begin{array}{c}\text { Fresh weight } \\
(\mathrm{g})\end{array}$ & $\begin{array}{c}\text { Soil moisture } \\
(\%)\end{array}$ & $\begin{array}{c}\text { Chlorophyll content } \\
(\mathrm{CC})\end{array}$ \\
\hline W.C & $20.0 \pm 1.1 \mathrm{a}$ & $11.7 \pm 0.5 \mathrm{a}$ & $9.5 \pm 0.4 \mathrm{~b}$ & $17.8 \pm 0.8 \mathrm{~b}$ & $70.0 \pm 3.9 \mathrm{~b}$ & $554.22 \pm 40 \mathrm{c}$ \\
V.C & $21.8 \pm 0.7 \mathrm{a}$ & $12.1 \pm 0.7 \mathrm{a}$ & $10.4 \pm 0.6 \mathrm{a}$ & $20.3 \pm 0.7 \mathrm{a}$ & $81.8 \pm 3.7 \mathrm{a}$ & $572.8 \pm 28 \mathrm{~b}$ \\
W.D & $14.0 \pm 0.5 \mathrm{~b}$ & $7.0 \pm 0.7 \mathrm{~b}$ & $6.2 \pm 0.6 \mathrm{c}$ & $6.9 \pm 0.7 \mathrm{~d}$ & $34.1 \pm 6.0 \mathrm{~d}$ & $531.57 \pm 34 \mathrm{~d}$ \\
V.D & $15.7 \pm 0.7 \mathrm{~b}$ & $7.7 \pm 0.7 \mathrm{~b}$ & $7.1 \pm 0.6 \mathrm{c}$ & $8.5 \pm 0.7 \mathrm{c}$ & $55.0 \pm 7.3 \mathrm{c}$ & $588.74 \pm 35 \mathrm{a}$ \\
\hline
\end{tabular}

W.C: Control with well-watered treatment, V.C: YNA59 inoculation well-watered treatment, W.D: Control drought stress, V.D: YNA59 inoculation with drought stress. Each data point is the mean of three replicates. Error bars represent standard errors. The bars presented with different letters are significantly different from each other as evaluated by DMRT analysis .

Effect of Isolate YNA59 on Plant Endogenous Phytohormones

Drought stress induced a significant increase in ABA ( 1.57 folds) and JA ( 5 folds) contents of broccoli plants (Figs. 5A and 5B). In isolate YNA59 inoculated broccoli, we observed a decrease in ABA ( 0.77 folds) and JA (0.7 folds) contents (Figs. 5A and 5B). However, in contrast to endogenous ABA and JA levels, increase of $20 \%$ in the endogenous SA contents was observed in isolate YNA59-inoculated broccoli plants (Fig. 5C).

\section{DAB Staining and Antioxidant Quantification in Broccoli}

Drought stresses leads to the generation of ROS i.e., $\mathrm{H}_{2} \mathrm{O}_{2}$, thereby causing oxidative damage to cells. DAB staining results showed more reddish-brown color development in drought stress control broccoli leaves than isolate YNA59-inoculated leaves. Thus, it was speculated that YNA59 treatment would help maintain the ROS equilibrium by minimizing excessive $\mathrm{H}_{2} \mathrm{O}_{2}$ accumulation in plant leaves (Fig. 6).

Excessive accumulation of ROS in broccoli was eliminated through chemical reactions of enzymatic antioxidant chemicals such as SOD, CAT, and APX and non-enzymatic antioxidant chemicals such as glutathione,

A

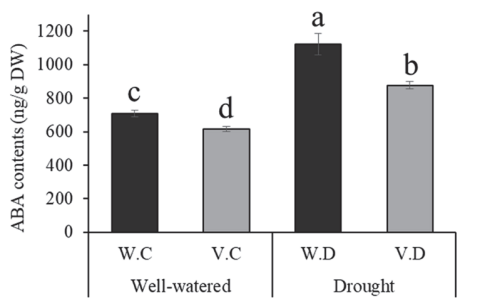

B

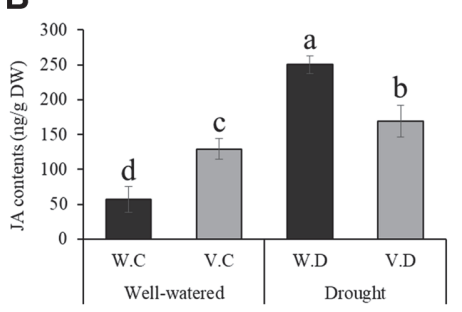

C

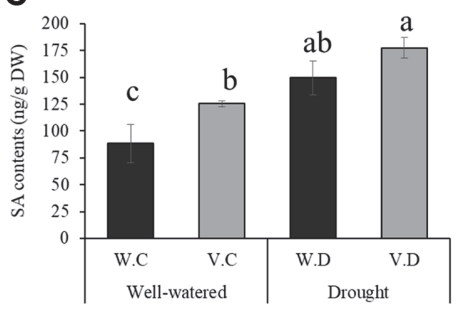

Fig. 5. Endogenous abscisic acid (ABA), jasmonic acid (JA), and salicylic acid (SA) quantification in broccoli plants inoculated with YUNA59. (A) Demonstrates ABA, (B) JA, and (C) shows the amount of SA under normal and drought stress. Each data point is the mean of at least three replicates. Error bars represent standard errors. The bars presented with different letters are significantly different from each other as evaluated by DMRT. 


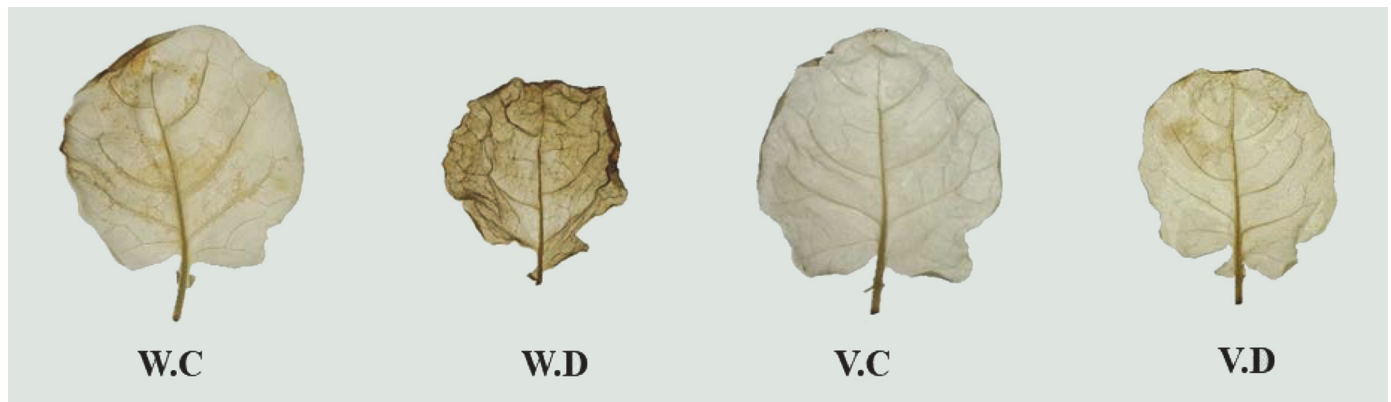

Fig. 6. Detection of hydrogen peroxide in broccoli leaves under normal and drought stress using 3,3'diaminobenzidine (DAB) staining method.

ascorbate, and polyphenol. This study was conducted to investigate the changes in antioxidant enzymes in broccoli during drought. SOD results showed that an increase in SOD content was observed under drought stress, however a significant increase in SOD content in isolate YNA59 treated broccoli plants were observed compared with drought stress and control plants (Fig. 7A). A similar trend was observed in the CAT and APX enzymatic activity, which showed higher proportions in drought stress broccoli plants inoculated with isolate YNA59 (Figs. 7 $\mathrm{B}$ and C). In contrast to SOD, CAT, and APX, GPX activity showed a significantly decreased value compared to drought stress and control plants (Fig. 7D).

\section{Identification of Bacterial Isolate YNA59}

Molecular identification and phylogenetic analysis of isolate YNA59 were performed by amplifying and sequencing the 16S rRNA after which it was compared to the database of known 16S rRNA gene sequences and BLAST search tool of NCBI data base/EzTaxon. Our results revealed that isolate YNA59 exhibited a high sequence identity (99\%) with Variovorax sp. and sequence was submitted to NCBI with GenBank accession no MN473279. Furthermore, the morphological characteristic of isolate YNA59 was investigated using field emission scanning electron microscopes (FE-SEM). Variovorax sp. YNA59 colony, which grew in LB broth was yellowish, smooth, and glistening (Fig. 8A). Microscopic observation of Variovorax sp. YNA59 displayed a curved rod-shaped, occurring as either single or pairs of cells and approximately $0.61 \times 2.04 \mu \mathrm{m}$ long (Fig. 8B).

A
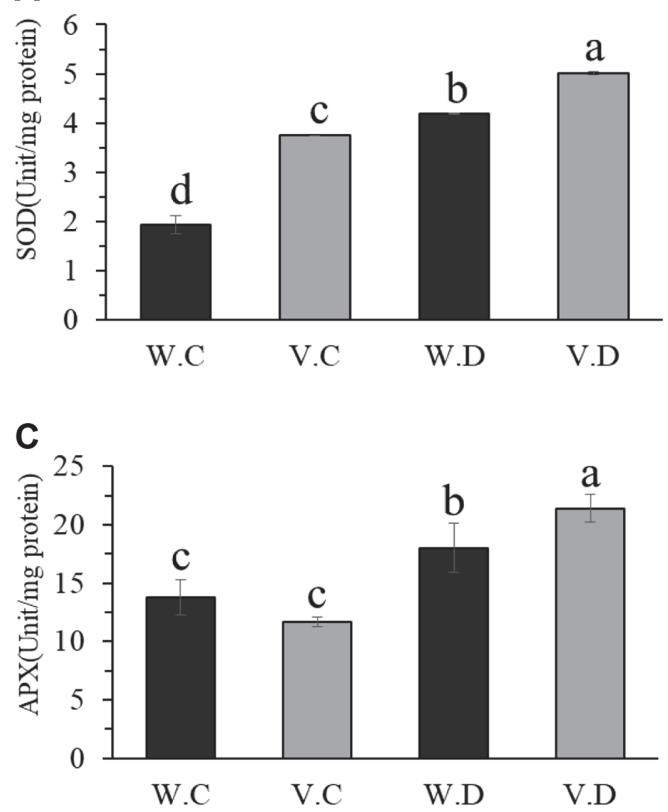

B
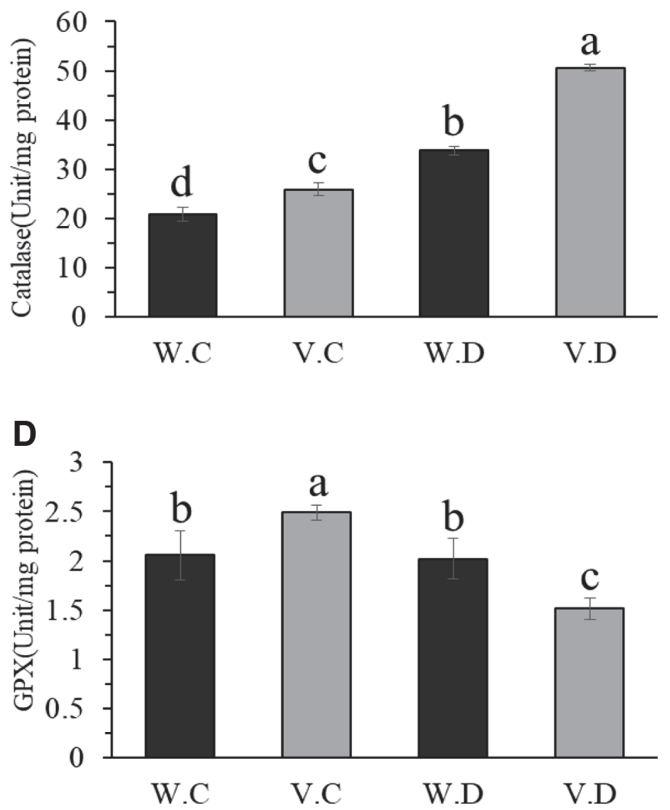

Fig. 7. The effect of bacterial isolates YNA59 on different antioxidants. (A) Superoxide dismutase (SOD); (B) Catalase (CAT); (C) Ascorbic peroxidase (APX), and (D) Guaiacol peroxidase (GPX) contents in broccoli plants under normal and drought stress. Each data point is the mean of three replicates. Error bars represent standard errors. The bars presented with different letters are significantly different from each other as evaluated by DMRT. 

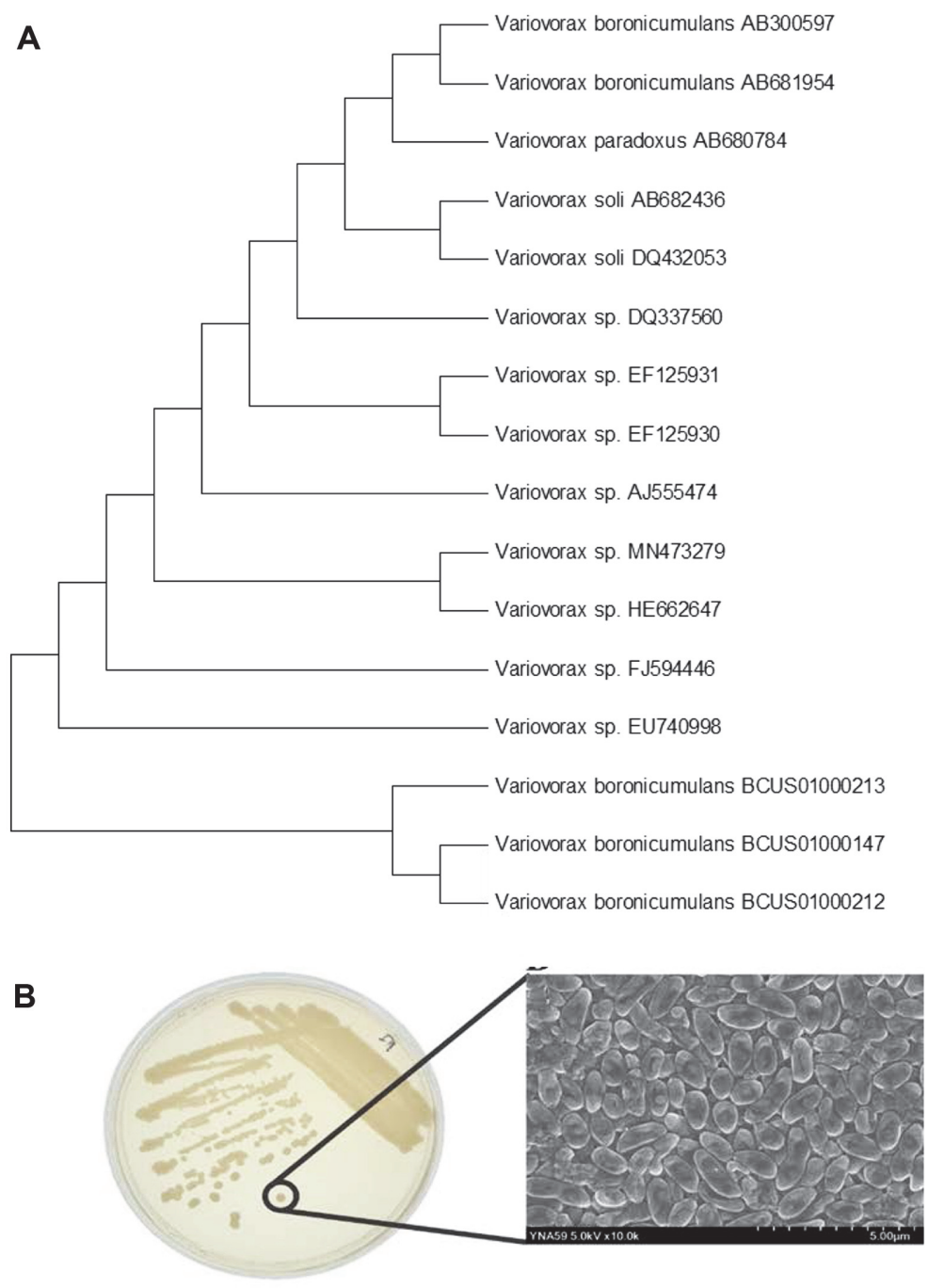

Fig. 8. Phylogenetic tree of YNA59 was constructed using $16 \mathrm{~S}$ rRNA sequences by neighbor joining (NJ) and maximum likelihood methods. (A) Phylogenetic tree of YNA59 was constructed using $16 \mathrm{~S}$ rRNA sequences by neighbor joining (NJ) and maximum likelihood methods; (B) Microscopic observation of YNA59 using a scanning electron microscope.

\section{Discussion}

The robust nutritional properties and different beneficial characteristics of broccoli have contributed to its increased demand worldwide. There is a need to boost the production of broccoli under drought conditions worldwide. To ease the adverse effects of drought stress, various methods including plant breeding, chemical fertilizer, tissue culture and genetic engineering have been used [19-23]. Similarly, several researchers have suggested the usage of drought tolerant microbes as a promising alternative to alleviate plant stress caused by drought stress. Recently the role of microbes in the management of drought stressor has begun gaining importance in wheat [41], pepper [42, 43], tomato [44], Chinese liquorice [45], Arabidopsis [46], timothy [47], and maize [48].

Broccoli, an important cultivated vegetable is sensitive to drought stress as its growth, yield, and quality are highly affected under this condition $[49,50]$. The decline in growth attributes under drought stress is because it directly affects photosynthesis and transpiration process [50]. Drought stress induces numerous physiological changes, such as abnormal metabolic processes, stomatal conductance, and hormone biosynthesis, which result in a disturbance of the normal growth and development $[51,52]$. In this study, our results revealed that drought stress inhibits plant growth and development; however, inoculation with the drought tolerant isolate YNA59 markedly alleviated the adverse effect of drought stress (Fig. 4, Table 1). The beneficial effects of selected bacterial isolate YNA59 on broccoli plants were likely due to plant growth-promoting traits such as PEG tolerance, EPS formation, and phytohormone ABA (Figs. 1 and 2). Isolate YNA59 have the ability of EPS formation and it was reported that EPS producing bacteria are able to maintain higher water potential around the roots and in soil, thus protecting the plants against drought stress $[53,54]$. 
Among other biochemical and physiological process of plants, photosynthesis is one of the most sensitive to abiotic stresses, including drought stress, that adversely affect chloroplast function and stomatal regulation [55, 56]. Plants have evolved several mechanisms to relieve drought stress, such as accumulation of osmolytes, reprogramming of phytohormone production, stomatal closure, and enhanced antioxidant defense system [55, 56]. Similarly, the chlorophyll results of our current study showed that a decrease in chlorophyll content was observed when the plants were subjected to drought stress; however, inoculation with YNA59 mitigated drought stress and increased the chlorophyll contents (Table 1). This increase in the chlorophyll content may also be explained by the increased photosynthetic leaf area (length and width) of plants inoculated with bacteria compared with that of non-inoculated plants, which was reduced due to drought stress (Table 1). Similar results were also reported in previous studies showing that the use of drought stress tolerant bacteria could increase the total chlorophyll content in basil, Chinese liquorice, maize, and rice plants under drought stress [45, 57-59].

Phytohormones play a vital role in plant by regulating plant growth and stress tolerance to maintain the viability of the plants under stress conditions. Studies have demonstrated that among other phytohormones, abscisic acid is actively involved in the response to drought stress. Under stress conditions, plants regulate stress hormones such as ABA through active chemical signals, which contribute to stomatal closure and water conservation [60, 61]. Plant-microbe interaction has been previously reported that mitigate the adverse effects of abiotic stress in plants through reducing ABA levels $[30,62,63]$. The results of our current study showed that the inoculation of isolate YNA59 enhance plant growth parameters and mitigate drought stress through the reduction of ABA accumulation (Fig. 5A). Similarly, SA and JA is another phyto-hormone that plays an important role in abiotic stress tolerance [64]. These phyto-hormones stimulate signal molecules and play anti-oxidative role to protect the plants from oxidative stress and ROS generation $[65,66]$. Previously, in various plants, including Kentucky blue grass, grapevine, potato, grape, Arabidopsis, bean, and tomato; the accumulation of SA has been associated with drought stress tolerance [67-71]. In this study, higher endogenous SA levels were observed in isolate YNA59inoculated broccoli plants under normal and drought stress (Fig. 5C). Our findings also support previous studies, which revealed that bacterial inocula enhances endogenous SA levels and decreases that of JA and enhances the growth attributes of plants under abiotic stress [24, 28, 31, 72]. Furthermore, drought stress increases the accumulation of ROS (singlet oxygen, superoxide anion, and $\mathrm{H}_{2} \mathrm{O}_{2}$ ), which cause cellular toxicity and lipid peroxidation along with protein degradation [49]. However, plants can reduce the damaging effect of ROS by the development of its antioxidant system consisting of glutathione reductase (GR), SOD, MDA, and APX, which can protect the plants against cellular stress, scavenge excess ROS and remove free radicals. The first antioxidant produced is SOD, which converts $\mathrm{O}_{2} \bullet-$ radicals to $\mathrm{H}_{2} \mathrm{O}_{2}$. This $\mathrm{H}_{2} \mathrm{O}_{2}$ is further detoxified by CAT and APX into water and oxygen [43]. Analysis of culture broth of isolate YNA59 indicates a significant amount of SOD, CAT, and APX activities (Fig. 3). Similarly, broccoli plants inoculated with YNA59 produced less ROS and exhibited increased antioxidant SOD, CAT, and APX activity while, GPX peroxidase activity showed opposed aspect with APX under drought stress (Fig. 7). Similar results were reported with the inoculation of drought tolerant bacteria, which significantly increased the activity of different ROS-scavenging enzymes in maize, basil, and rice [14, 5759].

\section{Conclusion}

Our current findings showed that drought tolerant rhizospheric isolate Variovorax sp. YNA59 is capable of producing different PGP traits, such as catalase assay, EPS formation, and PEG tolerance. Similarly, isolate YNA59 greatly enhanced the growth attributes, leaf width and length, chlorophyll content, and soil moisture content of broccoli plants. This improvement in plant growth was induced by isolate YNA59, which regulated plant endogenous phytohormones (ABA, JA, and SA) and antioxidants (APX, SOD, CAT, and GPX), as severe drought stress leads to excessive ROS, causing membrane and protein degradation. Based on the ameliorative qualities of isolate YNA59, it can be used for mitigating drought stress and as an ecofriendly bio-fertilizer for sustainable agriculture in drought-affected areas of the world.

\section{Acknowledgment}

This research was supported by the Basic Science Research Program through the National Research Foundation of Korea (NRF) funded by the Ministry of Education (2017R1D1A1B04035601).

\section{Conflict of Interest}

The authors have no financial conflicts of interest to declare.

\section{References}

1. Boyer J, Byrne P, Cassman K, Cooper M, Delmer D, Greene T, et al. 2013. The US drought of 2012 in perspective: A call to action. Glob. Food Secur. 2: 139-143.

2. Hussain M, Malik M, Farooq M, Ashraf M, Cheema M. 2008. Improving drought tolerance by exogenous application of glycinebetaine and salicylic acid in sunflower. J. Agron. Crop Sci. 194: 193-199.

3. Kaya MD, Okçu G, Atak M, Cıkılı Y, Kolsarıcı O. 2006. Seed treatments to overcome salt and drought stress during germination in sunflower (Helianthus annuus L.). Eur. J. Agron. 24: 291-295.

4. Nonami H. 1998. Plant water relations and control of cell elongation at low water potentials. J. Plant Res. 111: 373-382.

5. Zhang X, Lei L, Lai J, Zhao H, Song W. 2018. Effects of drought stress and water recovery on physiological responses and gene expression in maize seedlings. BMC Plant Biol. 18: 68.

6. Daryanto S, Wang L, Jacinthe P-A. 2016. Global synthesis of drought effects on maize and wheat production. PLoS One 11: e0156362. 
7. Farooq M, Gogoi N, Barthakur S, Baroowa B, Bharadwaj N, Alghamdi SS, et al. 2017. Drought stress in grain legumes during reproduction and grain filling. J. Agron. Crop Sci. 203: 81-102.

8. Grene R. 2002. Oxidative stress and acclimation mechanisms in plants. Arabidopsis Book. 1: e0036. doi:10.1199/tab.0036.1

9. Hasanuzzaman M, Hossain MA, da Silva JAT, Fujita M. 2012. Plant response and tolerance to abiotic oxidative stress: Antioxidant defense is a key factor, pp. 261-315. In Venkateswarlu B, Shanker AK, Shanker C, Maheswari M (eds.), Crop Stress and its Management: Perspectives and Strategies, Ed. Springer Netherlands, Dordrecht

10. Kang S-M, Joo G-J, Hamayun M, Na C-I, Shin D-H, Kim HY, et al. 2009. Gibberellin production and phosphate solubilization by newly isolated strain of Acinetobacter calcoaceticus and its effect on plant growth. Biotechnol. Lett. 31: 277-281.

11. Kang S-M, Khan AL, Hamayun M, Hussain J, Joo G-J, You Y-H, et al. 2012. Gibberellin-producing Promicromonospora sp. SE188 improves Solanum lycopersicum plant growth and influences endogenous plant hormones. J. Microbiol.50: 902-909.

12. Armada E, Roldán A, Azcon R. 2014. Differential activity of autochthonous bacteria in controlling drought stress in native Lavandula and Salvia plants species under drought conditions in natural arid soil. Microb. Ecol. 67: 410-420.

13. Kang S-M, Radhakrishnan R, Khan AL, Kim M-J, Park J-M, Kim B-R, et al. 2014. Gibberellin secreting rhizobacterium, Pseudomonas putida H-2-3 modulates the hormonal and stress physiology of soybean to improve the plant growth under saline and drought conditions. Plant Physiol. Biochem. 84: 115-124.

14. Sandhya V, Ali SZ, Grover M, Reddy G, Venkateswarlu B. 2010. Effect of plant growth promoting Pseudomonas spp. on compatible solutes, antioxidant status and plant growth of maize under drought stress. Plant Growth Regul. 62: 21-30.

15. Heidari M, Mousavinik SM, Golpayegani A. 2011. Plant growth promoting rhizobacteria (PGPR) effect on physiological parameters and mineral uptake in basil (Ociumum basilicm L.) under water stress. ARPN J. Agric. Biol. Sci. 6: 6-11.

16. Khan MAM, Ulrichs C, Mewis I. 2011. Effect of water stress and aphid herbivory on flavonoids in broccoli (Brassica oleracea var. italica Plenck). J. Appl. Bot. Food Qual. 84: 178-182.

17. Erken O, Oztokat C. 2010. Effects of water stress on yield and some quality parameters of Broccoli, pp. 231-237. In 2nd International Symposium on Sustainable Development. Science book

18. Toscano S, Trivellini A, Cocetta G, Bulgari R, Francini A, Romano D, et al. 2019. Effect of preharvest abiotic stresses on the accumulation of bioactive compounds in horticultural produce. Front Plant Sci. 10: 1212.

19. Kałużewicz A, Krzesiński W, Spiżewski T, Zaworska A. 2017. Effect of biostimulants on several physiological characteristics and chlorophyll content in broccoli under drought stress and re-watering. Not. Bot. Horti. Agrobo. 45: 197-202.

20. Munawar A, Akram NA, Ahmad A, Ashraf M. 2019. Nitric oxide regulates oxidative defense system, key metabolites and growth of broccoli (Brassica oleracea L.) plants under water limited conditions. Sci. Hortic. 254: 7-13.

21. Ertan Y, Huseyin K, Metin T, Atilla D, Fahrettin G. 2011. Growth, nutrient uptake, and yield promotion of broccoli by plant growth promoting rhizobacteria with manure. HortScience 46: 932-936.

22. Yildirim E, Karlidag H, Turan M, Donmez M. 2010. Potential use of plant growth promoting rhizobacteria in organic broccoli (Brassica oleracea L., var. italica) production. In Ecofruit 14th International Conference on Organic Fruit-Growing, pp. 227-235. Proceedings for the Conference, Hohenheim, Germany.

23. El-Nemr M, Zaki M, Tantawy A, Abdel-Mawgoud A. 2011. Enhancement of growth and production of broccoli crop using bionutritional foliar compound. Aust. J. Basic Appl. Sci. 5: 2578-2583.

24. Khan MA, Ullah I, Waqas M, Hamayun M, Khan AL, Asaf S, et al. 2019. Halo-tolerant rhizospheric Arthrobacter woluwensis AK1 mitigates salt stress and induces physio-hormonal changes and expression of GmST1 and GmLAX3 in soybean. Symbiosis. 77: 9-21.

25. Khan MA, Asaf S, Khan AL, Jan R, Kang S-M, Kim K-M, et al. 2019. Rhizobacteria AK1 remediates the toxic effects of salinity stress via regulation of endogenous phytohormones and gene expression in soybean. Biochem. J. 476: 2393-2409.

26. Mun B-G, Lee W-H, Kang S-M, Lee S-U, Lee S-M, Lee DY, et al. 2020. Streptomyces sp. LH 4 promotes plant growth and resistance against Sclerotinia sclerotiorum in cucumber via modulation of enzymatic and defense pathways. Plant Soil. 448: 87-103.

27. Freeman D, Falkiner F, Keane C. 1989. New method for detecting slime production by coagulase negative staphylococci. J. Clin. Pathol. 42: 872-874.

28. Khan MA, Asaf S, Khan AL, Ullah I, Ali S, Kang SM, et al. 2019. Alleviation of salt stress response in soybean plants with the endophytic bacterial isolate Curtobacterium sp. SAK1. Ann. Microbiol. 69: 797-808.

29. Kang S-M, Radhakrishnan R, Lee S-M, Park Y-G, Kim A-Y, Seo C-W, et al. 2015. Enterobacter sp. SE992-induced regulation of amino acids, sugars, and hormones in cucumber plants improves salt tolerance. Acta Physiol. Plant. 37: 149.

30. Park Y-G, Mun B-G, Kang S-M, Hussain A, Shahzad R, Seo C-W, et al. 2017. Bacillus aryabhattai SRB02 tolerates oxidative and nitrosative stress and promotes the growth of soybean by modulating the production of phytohormones. PLoS One. 12: e0173203.

31. Khan MA, Asaf S, Khan AL, Jan R, Kang SM, Kim KM, et al. 2020. Extending thermotolerance to tomato seedlings by inoculation with SA1 isolate of Bacillus cereus and comparison with exogenous humic acid application. PLoS One. 15: e0232228.

32. Khan MA, Hamayun M, Iqbal A, Khan SA, Hussain A, Asaf S, et al. 2018. Gibberellin application ameliorates the adverse impact of short-term flooding on Glycine max L. Biochem. J. 475: 2893-2905.

33. Khan MA, Khan AL, Imran QM, Asaf S, Lee S-U, Yun B-W, et al. 2019. Exogenous application of nitric oxide donors regulates shortterm flooding stress in soybean. PeerJ. 7: e7741.

34. Jan R, Khan MA, Asaf S, Lee IJ, Kim KM. 2019. Metal resistant endophytic bacteria reduces cadmium, nickel toxicity, and enhances expression of metal stress related genes with improved growth of Oryza sativa, via regulating its antioxidant machinery and endogenous hormones. Plants (Basel). 8: 363.

35. Frahry G, Schopfer P. 2001. NADH-stimulated, cyanide-resistant superoxide production in maize coleoptiles analyzed with a tetrazolium-based assay. Planta 212: 175-183.

36. Bradford MM. 1976. A rapid and sensitive method for the quantitation of microgram quantities of protein utilizing the principle of protein-dye binding. Anal. Biochem. 72: 248-254

37. Chaoui A, Mazhoudi S, Ghorbal MH, El Ferjani E. 1997. Cadmium and zinc induction of lipid peroxidation and effects on antioxidant enzyme activities in bean (Phaseolus vulgaris L.). Plant Sci. 127: 139-147.

38. Gowrishankar S, Pandian SK. 2017. Modulation of Staphylococcus epidermidis (RP62A) extracellular polymeric layer by marine cyclic dipeptide-cyclo(l-leucyl-1-prolyl) thwarts biofilm formation. Biochim. Biophys. Acta Biomembr. 1859: 1254-1262.

39. Russell DW, Sambrook J. 2001. Molecular cloning: a laboratory manual Vol. 1, pp. 112. Cold Spring Harbor, NY: Cold Spring Harbor Laboratory.

40. Tamura K, Stecher G, Peterson D, Filipski A, Kumar S. 2013. MEGA6: Molecular evolutionary genetics analysis version 6.0. Mol. Biol. Evol. 30: 2725-2729.

41. Yandigeri MS, Meena KK, Singh D, Malviya N, Singh DP, Solanki MK, et al. 2012. Drought-tolerant endophytic actinobacteria promote growth of wheat (Triticum aestivum) under water stress conditions. Plant Growth Regul. 68: 411-420.

42. Marasco R, Rolli E, Ettoumi B, Vigani G, Mapelli F, Borin S, et al. 2012. A drought resistance-promoting microbiome is selected by root system under desert farming. PLoS One. 7: e48479-e48479.

43. Lim J-H, Kim S-D. 2013. Induction of drought stress resistance by multi-functional PGPR Bacillus licheniformis K11 in pepper. Plant Pathol. J. 29: 201-208. 
44. Mayak S, Tirosh T, Glick BR. 2004. Plant growth-promoting bacteria that confer resistance to water stress in tomatoes and peppers. Plant Sci. 166: 525-530.

45. Zhang W, Xie Z, Zhang X, Lang D, Zhang X. 2019. Growth-promoting bacteria alleviates drought stress of G. uralensis through improving photosynthesis characteristics and water status. J. Plant Interact. 14: 580-589.

46. Cho SM, Kang BR, Han SH, Anderson AJ, Park J-Y, Lee Y-H, et al. 2008. 2R, 3R-butanediol, a bacterial volatile produced by Pseudomonas chlororaphis O6, is involved in induction of systemic tolerance to drought in Arabidopsis thaliana. Mol. Plant Microbe. Interact. 21: 1067-1075.

47. Gagné-Bourque F, Bertrand A, Claessens A, Aliferis KA, Jabaji S. 2016. Alleviation of drought stress and metabolic changes in timothy (Phleum pratense L.) colonized with Bacillus subtilis B26. Front. Plant Sci. 7: 584.

48. Casanovas EM, Barassi CA, Sueldo RJ. 2002. Azospirillum inoculation mitigates water stress effects in maize seedlings. Cereal Res. Commun. 343-350.

49. Kiani S, Babaeianjelodar N, Bagheri N, Najafizarrini H. 2018. Effect of mannitol stress on morphological, biochemical and polyphenol parameters in broccoli sprouts (Brassica oleracea var. Italica). Appl. Ecol. Environ. Res. 16: 2043-2058.

50. Beacham AM, Hand P, Pink DA, Monaghan JM. 2017. Analysis of Brassica oleracea early stage abiotic stress responses reveals tolerance in multiple crop types and for multiple sources of stress. J. Sci. Food Agric. 97: 5271-5277.

51. Rahbarian R, Khavari-Nejad R, Ganjeali A, Bagheri A, Najafi F. 2011. Drought stress effects on photosynthesis, chlorophyll fluorescence and water relations in tolerant and susceptible chickpea (Cicer arietinum L.) genotypes. Acta Biol. Crac. Ser. Bot. 53: 4756.

52. Wu H, Wu X, Li Z, Duan L, Zhang M. 2012. Physiological evaluation of drought stress tolerance and recovery in cauliflower (Brassica oleracea L.) seedlings treated with methyl jasmonate and coronatine. J. Plant Growth Regul. 31: 113-123.

53. Vurukonda SSKP, Vardharajula S, Shrivastava M, SkZ A. 2016. Enhancement of drought stress tolerance in crops by plant growth promoting rhizobacteria. Microbiol. Res. 184: 13-24.

54. Selvakumar G, Panneerselvam P, Ganeshamurthy AN. 2012. Bacterial mediated alleviation of abiotic stress in crops, pp. 205-224. Bacteria in agrobiology: Stress management, Ed. Springer,

55. Wang Z, Li G, Sun H, Ma L, Guo Y, Zhao Z, et al. 2018. Effects of drought stress on photosynthesis and photosynthetic electron transport chain in young apple tree leaves. Biol. Open. 7: bio035279.

56. Li J, Cang Z, Jiao F, Bai X, Zhang D, Zhai R. 2017. Influence of drought stress on photosynthetic characteristics and protective enzymes of potato at seedling stage. J. Saudi Soc. Agric. Sci. 16: 82-88.

57. Heidari M, Golpayegani A. 2012. Effects of water stress and inoculation with plant growth promoting rhizobacteria (PGPR) on antioxidant status and photosynthetic pigments in basil (Ocimum basilicum L.). J. Saudi Soc. Agric. Sci. 11: 57-61.

58. Vardharajula S, Ali SZ, Grover M, Reddy G, Bandi V. 2011. Drought-tolerant plant growth promoting Bacillus spp.: effect on growth, osmolytes, and antioxidant status of maize under drought stress. J. Plant Interact. 6: 1-14.

59. Gusain YS, Singh U, Sharma A. 2015. Bacterial mediated amelioration of drought stress in drought tolerant and susceptible cultivars of rice (Oryza sativa L.). Afr. J. Biotechnol. 14: 764-773.

60. de Ollas C, Dodd IC. 2016. Physiological impacts of ABA-JA interactions under water-limitation. Plant Mol. Biol. 91: 641-650.

61. Verma V, Ravindran P, Kumar PP. 2016. Plant hormone-mediated regulation of stress responses. BMC Plant Biol. 16: 86-86.

62. Tiwari S, Prasad V, Chauhan PS, Lata C. 2017. Bacillus amyloliquefaciens confers tolerance to various abiotic stresses and modulates plant response to phytohormones through osmoprotection and gene expression regulation in rice. Front. Plant Sci. 8: 1510.

63. Curá JA, Franz DR, Filosofía JE, Balestrasse KB, Burgueño LE. 2017. Inoculation with Azospirillum sp. and Herbaspirillum sp. bacteria increases the tolerance of maize to drought stress. Microorganisms. 5: 41.

64. Koo YM, Heo AY, Choi HW. 2020. Salicylic acid as a safe plant protector and growth regulator. Plant Pathol. J. 36: 1-10.

65. Wang Q-J, Sun H, Dong Q-L, Sun T-Y, Jin Z-X, Hao Y-J, et al. 2016. The enhancement of tolerance to salt and cold stresses by modifying the redox state and salicylic acid content via the cytosolic malate dehydrogenase gene in transgenic apple plants. Plant Biotechnol. J. 14: 1986-1997.

66. Yang Y, Qi M, Mei C. 2004. Endogenous salicylic acid protects rice plants from oxidative damage caused by aging as well as biotic and abiotic stress. Plant J. 40: 909-919.

67. Wang LJ, Fan L, Loescher W, Duan W, Liu GJ, Cheng JS, et al. 2010. Salicylic acid alleviates decreases in photosynthesis under heat stress and accelerates recovery in grapevine leaves. BMC Plant Biol. 10: 34.

68. Lopez-Delgado H, Dat JF, Foyer CH, Scott IM. 1998. Induction of thermotolerance in potato microplants by acetylsalicylic acid and $\mathrm{H}_{2} \mathrm{O}_{2}$. J. Exp. Bot. 49: 713-720.

69. Senaratna T, Touchell D, Bunn E, Dixon K. 2000. Acetyl salicylic acid (Aspirin) and salicylic acid induce multiple stress tolerance in bean and tomato plants. Plant Growth Regul. 30: 157-161.

70. Clarke SM, Mur LAJ, Wood JE, Scott IM. 2004. Salicylic acid dependent signaling promotes basal thermotolerance but is not essential for acquired thermotolerance in Arabidopsis thaliana. Plant J. 38: 432-447.

71. Wang L-J, Li S-H. 2006. Salicylic acid-induced heat or cold tolerance in relation to $\mathrm{Ca}^{2+}$ homeostasis and antioxidant systems in young grape plants. Plant Sci. 170: 685-694.

72. Shahzad R, Waqas M, Khan AL, Asaf S, Khan MA, Kang S-M, et al. 2016. Seed-borne endophytic Bacillus amyloliquefaciens RWL-1 produces gibberellins and regulates endogenous phytohormones of Oryza sativa. Plant Physiol. Biochem. 106: 236-243. 